\title{
Estética teológica e a renovação litúrgica
}

\author{
Theological aesthetics and liturgical renewal
}

Tiago Geyrdenn de Oliveira Gomes

\section{Resumo}

Ao relacionar o tema da estética teológica com a renovação litúrgica, é necessário apresentar o conceito de estética. Para tanto, será apresentado a partir do teólogo Hans Urs von Balthasar. O eixo de sua estética teológica é a Cristologia. O teólogo pretende mostra a beleza de Cristo ao mundo. A reflexão teológica de Balthasar nos leva a uma reflexão acerca da liturgia, uma vez que esta permite vislumbrar de modo mistérico a figura do Cristo. A liturgia deve expressar tal glória e conduzir o cristão ao mistério celebrado, ela é mistagógica. Neste sentido, apresenta-se o movimento litúrgico como impulsionador de uma reforma na liturgia que pudesse expressar melhor esta beleza cristológica no mistério celebrado. Ao apresentar o conceito de beleza na perspectiva teológica para depois apresentar a renovação litúrgica, o objetivo é mostrar como ambos se relacionam e como se pode melhor acentuar a essência do mistério pascal com o aprofundamento teológico acerca da liturgia. A pesquisa é de ordem bibliográfica a partir de revisão de literatura.

Palavras-chave: Estética teológica. Movimento litúrgico. Renovação litúrgica. Hans Urs von Balthasar.

\section{Abstract}

This paper describes the theme of theological aesthetics with the liturgical renewal. It presents the concept of aesthetics from of the theologian Hans Urs von Balthasar. The axis of his theological aesthetics is the Christology. The theologian want to expose the beauty of Christ to the world. Theological 
reflection of Balthasar leads to a reflection on the liturgy, since it provides a glimpse mysterious of the face of Christ. The liturgy should express such glory and lead the christian to the mystery celebrated, it is mystagogic. In this way, we present the liturgical movement as a catalyst for reform in the liturgy that could better express this beauty in the christological mystery celebrated. To introduce the concept of beauty in theological perspective and then present the liturgical renewal, the aim is to present how both relate and how to best accentuate the essence of the paschal mystery with the theological study about the liturgy. The research is by literary order from of literature review.

Keywords: Theological aesthetics. Liturgical movement. Liturgical renewal. Hans Urs von Balthasar.

\section{Introdução}

A constituição Sacrosanctum Concilium foi o primeiro documento a ser aprovado pelo Concílio Vaticano II. Ele traz em si a concretização de um trabalho de renovação elaborado durante o período de quase um século antes do Concílio. O objetivo era uma renovação da liturgia que retomasse o sentido original da mesma, isto é, a compreensão que a comunidade primitiva tinha do mistério pascal celebrado. Sentido que parece ter sido obscurecido ao longo do tempo e relegado a liturgia a uma função secundária para a vida da Igreja.

Constatando a realidade eclesial pensadores e pesquisadores se debruçaram sobre o tema da liturgia e desencadearam um processo histórico de renovação que culminou no Concílio Vaticano II. Muitas obras e esforços foram empreendidos para que o sentido cristológico e eclesiológico da liturgia adquirissem novo estatuto na Igreja Católica. O objetivo deste trabalho é apresentar este percurso histórico que fomentou a necessidade de uma reforma litúrgica e relacioná-lo com o tema da estética teológica. O objetivo é mostrar como ambos se relacionam e como se pode melhor acentuar a essência do mistério pascal com o aprofundamento teológico acerca da liturgia.

Para o tema da estética será utilizado o pensamento do teólogo Hans Urs von Balthasar. Este teólogo apresenta em sua obra uma centralidade cristológica. O eixo de sua estética teológica é a Cristologia, o teólogo pretende mostra a beleza de Cristo ao mundo. A partir de uma definição do termo estética, 
aborda-se o mesmo no pensamento balthasariano. Em seguida, relaciona-se a definição de estética com uma compreensão teológica acerca da liturgia. Tal compreensão não é estática, mas se foi alterando em várias épocas. Isto conduz ao movimento litúrgico, que preconizou o retorno da liturgia como fundamento da vida eclesial. O movimento litúrgico culmina na renovação litúrgica empreendida pelo Vaticano II.

\section{Definição de Estética teológica}

Para o cristão parece mais ou menos claro que é possível encontrar a beleza na celebração dos sacramentos; aí já se experimenta a glória divina, embora que seja apenas na sensibilidade. Ao abordar o tema da beleza como condutora para Deus na liturgia, inicialmente faz-se necessário apresentar o conceito de estética. Definir possivelmente o que vem a ser uma estética teológica, buscando uma fundamentação no discurso teológico, para em seguida mostrar a liturgia e sua beleza, ou a possibilidade da beleza da liturgia como condutora para Deus.

Ao falar de estética teológica, ou de estética simplesmente, vem atrelado necessariamente o conceito ou ideia de beleza. Estas aparecem indissociáveis. Beleza é

Propriedade estética comumente pensada como sendo uma espécie de valor estético. Nesta qualidade, ela tem sido diversamente pensada como sendo uma propriedade simples, que não pode ser definida em termos de quaisquer outras propriedades; uma propriedade ou um conjunto de propriedades de um objeto que tornam o objeto capaz de produzir certa espécie de experiência prazerosa naqueles que a percebem adequadamente; ou ainda tudo aquilo que produz uma espécie particular de experiência prazerosa, embora aquilo que produz a experiência possa variar de indivíduo para indivíduo. ${ }^{1}$

Há uma relação com a estética, bem como com os sentidos e com o prazer. As propriedades filosóficas da beleza remetem à simplicidade e à unicidade, numa perspectiva platônica, que conduzem ao Belo. O dicionário de teologia conceitua beleza assim:

${ }^{1}$ FEAGIN, S. L. "Beleza”. In: AUDI, R. (Ed.). Dicionário de Filosofia de Cambridge. São Paulo: Paulus, 2006, pp. 74-75. 
A beleza é ponto de partida para a contemplação do ser. Constitui a última palavra que o intelecto consegue pronunciar antes de ceder a vez, racionalmente, ao saber do incompreensível. Toda pessoa sabe o que é beleza, porque ela se dá por si, simplesmente, naquela evidência que deixa intuir, num todo único, a presença da bondade e da verdade do próprio ser. ${ }^{2}$

Esta definição parte também dos sentidos, mas abre aqui uma perspectiva maior, de alcance do ser. A beleza é imediata, relacionada com o bem e com a verdade. Relacionar-se com ela, ser capaz de apreendê-la, é de certo modo ter acesso ao bom e à verdade. Neste sentido a estética teológica associa o belo a Deus. Para Balthasar, teológico que nos conduzirá nesta reflexão, a beleza é a figura de Deus manifestada em Jesus Cristo ${ }^{3}$. O caminho da beleza é a primeira e mais privilegiada via de conhecimento da divindade.

La Via della bellezza, a partire dall'esperienza semplicissima dell'incontro con la bellezza che suscita stupore, può aprire la strada della ricerca di Dio e disporre il cuore e la mente all'incontro col Cristo, Bellezza della Santità Incarnata offerta da Dio agli uomini per la loro Salvezza. Essa invita i nuovi Agostino del nostro tempo, cercatori insaziabili d'amore, di verità e di bellezza, ad elevarsi dalla bellezza sensibile alla Bellezza eterna e a scoprire con fervore il Dio Santo Artefice di ogni bellezza. ${ }^{4}$

O Cristo é o revelador da beleza divina em plenitude, aquele que conduz para o autor de toda beleza. A revelação, no cristianismo, está contida na Sagrada Escritura. Faz-se necessário abordar do ponto de visto bíblico o conceito de beleza. Na Sagrada Escritura esta perpassa toda a obra da criação e se revela plenamente no Verbo encarnado.

Para a Bíblia, enquanto palavra de revelação, a Beleza estende-se de Deus a todo criado. Beleza e bondade são sinônimos, porque ambas deixam perceber tanto a ação criadora de Jhwh quanto seu fazer-se conhecer como

\footnotetext{
${ }^{2}$ FISICHELLA, R. “Beleza”. In: LATOURELLE, R.; FISICHELLA, R. (Ed.). Dicionário De Teologia Fundamental. Petrópolis: Vozes, 1994, pp. 107-108.

${ }^{3}$ Cf. FISICHELLA, R. "Hans Urs von Balthasar”. In: LACOSTE, J-Y. (Ed.). Dicionário Crítico de Teologia. São Paulo: Paulinas, 2004, pp. 231-238.

${ }^{4}$ PONTIFÍCIO CONSELHO PARA A CULTURA. "La Via pulchritudinis: Cammino privilegato di evangelizzacione e di dialogo". Disponível em: <http://www.vatican.va/roman_curia/ pontifical_councils/cultr/documents/rc_pc_cultr_doc_20060327_plenary-assembly_finaldocument_it.html $>$. Acesso em 17 de outubro de 2014.
} 
verdadeiro Deus. Jhwh, que liberta da escravidão e da morte (Ex 3,8;18,9), manifesta a Beleza e a bondade de seu amor; Jhwh, que introduz no "belo" país onde corre leite e mel (Dt 8, 7-10) é aquele que revela sua fidelidade à palavra dada. ${ }^{5}$

Cristo não apenas revela tal beleza, mas manifesta a glória do Pai. A ação de Jesus de Nazaré é ponto culminante desta revelação. A glória de Deus irradia-se em seu agir, a começar por sua encarnação. A língua hebraica pode iluminar esta reflexão.

A terminologia hebraica, na indeterminação da palavra tôb, traduzida indiferentemente por kalós [belo] e agathós [bom], especifica, porém, ulteriormente, o sentido e o conteúdo da beleza de Deus, recorrendo ao termo kabôd. Kabôd é glória da irradiação do revelar-se de Deus à humanidade. É o que permite perceber o esplendor da beleza. Beleza impossível de ser descrita e vista diretamente (Ex 33, 18-23), mas dada somente para poder ser contemplada e, além disso, em sua manifestação reflexa (Ex 34, 30-35). Esta mesma glória é hoje a beleza que os crentes vêem refletida no rosto do Crucificado, "o mais belo entre os filhos dos homens" (Sl 44,2). ${ }^{6}$

Como afirmado anteriormente o tema da beleza não se encontra no centro da literatura bíblica. Contudo, o conceito de criação ou obra divina expressa e ocupa este lugar na Sagrada Escritura. A glória de Deus pode ser percebida sensitivamente por meio da criação.

Falta na história da teologia um tratado específico sobre a beleza, provavelmente porque o dado do criado já era dado como pressuposto de tal conceito, ou porque a teologia se ocupou demais com as definições fundamentais da fé ante as heresias. Certo é que na antiguidade e no medievo pouco se encontra sobre a beleza, salvo na literatura e na poesia. Na contemporaneidade um teólogo que coloca no centro de seu sistema a beleza é Hans Urs von Balthasar, que lança uma luz e abre uma perspectiva nova neste sentido.

${ }^{5}$ FISICHELLA, R. “Beleza”. In: LATOURELLE, R.; FISICHELLA, R. (Eds.). Dicionário De Teologia Fundamental. Petrópolis: Vozes, 1994, pp. 107-108.

${ }^{6}$ FISICHELLA, R. "Beleza”. In: LATOURELLE, R.; FISICHELLA, R. (Eds.). Dicionário De Teologia Fundamental. Petrópolis: Vozes, 1994, pp. 107-108. 


\section{Von Balthasar e a estética teológica}

Para este trabalho será abordado o pensamento do teólogo Hans Urs von Balthasar ${ }^{7}$. O sistema teológico de Balthasar é construído sob a forma de trilogia. Ele coloca a possibilidade de um fazer teológico a partir dos transcendentais, ou seja, há uma leitura ou abordagem do evento da revelação a partir destes transcendentais. Acerca destes afirma-se que

tomando a forma de uma trilogia, funda-se na utilização teológica de dois transcendentais, o verdadeiro (verum) e o bem (bonum), e de um terceiro conceito ao qual reconhecia também um estatuto transcendental, o belo (pulchrum), noções que têm a ordem invertida para conceder a prioridade ao pulchrum, e que organizam respectivamente uma estética teológica, uma teo-dramática e uma teo-lógica. ${ }^{8}$

Com isso pretende mostrar que a revelação é plena de sentido. O centro desta revelação é Cristo enquanto resposta existencial para o mundo, enquanto verdade que guia a existência humana. Balthasar pode ser definido como um apologeta da atualidade. Neste sentido, ele deseja falar ao homem de sua época.

O desejo de mostrar a revelação cristã antes de tudo à luz do pulchrum e portanto do bonum e do verum - na unidade dos três transcendentais - foi intencionalmente movido pela constatação de que o homem contemporâneo - e nele o filósofo e o teólogo - não estavam mais em condições de perceber e transmitir a inexaurível riqueza da revelação, por estar distraído por outras formas e expectativas que, de qualquer forma, o levavam para longe de um progresso verdadeiro, na medida em que o afastavam de si mesmo, de suas raízes e, portanto, de seu futuro verdadeiro. ${ }^{9}$

Será abordado aqui o primeiro transcendental, a estética. O pulchrum é o primeiro passo da compreensão do mistério. É também o modo adequado

\footnotetext{
${ }^{7}$ Não será uma investigação em demasia da obra do mesmo, não cabe neste trabalho, também não se ajusta e esta problemática, contudo serve para fundamentar o conceito de beleza nesta perspectiva teológica, embora que Balthasar seja abordado de certo modo en passant.

${ }^{8}$ FISICHELLA, R. "Hans Urs von Balthasar". In: LACOSTE, J-Y. (Ed.). Dicionário Crítico de Teologia. São Paulo: Paulinas, 2004, pp. 231-238.

${ }^{9}$ FISICHELLA, R. Introdução à Teologia Fundamental. São Paulo: Loyola, 2011, p. 132.
} 
de levá-lo ao homem atual, ou seja, o modo adequado de levar a fé cristã e de dialogar com a contemporaneidade. O teólogo aborda a glória divina que define seu projeto teológico. Este parte do conceito de beleza teológica e do transcendental que pode ser definido como estética. O próprio Balthasar fala que

Soulignons encore une fois que l'objet formel de cette enquête est la gloire de la révélation divine, dans la diversité de ses manifestations et des manières de la concevoir, et en tour cela beauté théologique elle-même, dans sa transcendance qui dépasse tous les schèmes de la beauté profane. ${ }^{10}$

Nesta relação entre os transcendentais, o ponto de partida se dá com o pulchrum, isto é, a beleza ou estética como acesso privilegiado. Como "intuição original" para compreensão da revelação. Contudo, a estética deve ser explicitada por uma "dramática" e por uma "lógica" teológica. Aqui o âmbito da percepção é o momento inicial da reflexão. "Segundo Balthasar, a percepção é possível na medida em que Deus revela sua Gestalt. Esta é a expressão do absoluto, a revelação que parte de si, mas "remete" à sua essência e à sua profundeza constitutivas. E nessa revelação, o conteúdo (Gehalt) é idêntico à figura que exprime (Gestalt)" "11.A revelação se dá plenamente no Cristo, figura por excelência da glória divina. Cristo é a gestalt que favorece e que permite ao homem compreender ou perceber o ser.

Aquilo que aparece ao homem em Cristo é o ser em plenitude, em sua essência e é também o próprio homem enquanto se deixa tocar por esta manifestação. Em Cristo "se realiza de uma vez por todas na história o unicum que permite constatar a irradiação da glória de Deus na natureza de um homem, e isso devido ao fato de que ele é essencialmente e trinitariamente igual a Deus" ${ }^{\prime 2}$. É o evento Cristo que permite a Balthasar definir a estética como tal momento, chave de interpretação de sua estética teológica. Para o teólogo

tout ce qui est beau et splendide dans le monde est l'epiphanie, le rayonnement, l'éclat de principes d'être puissants et cachés jaillissant dans une figure expresive. Dès lors révélation du Dieu caché, absolument libre et souverain, apparaissant sous une forme terrestre dans la parole et dans

\footnotetext{
${ }^{10}$ BALTHASAR, H. U. La Gloire et la Croix, les aspects esthétiques de la révélation. Paris: Éditions Aubier-Montaigne, 1965, p. 19.

${ }^{11}$ FISICHELLA, R. "Hans Urs von Balthasar". In: LACOSTE, J-Y. (Ed.). Dicionário Crítico de Teologia. São Paulo: Paulinas, 2004, pp. 231-238.

${ }^{12}$ FISICHELLA, R. Introdução à Teologia Fundamental. São Paulo: Loyola, 2011, p. 138
} 
l'histoire, et finalement dans la figure de l'homme, ne peut constituer que le terme suréminent d'un rapport d'analogie avec la beauté naturelle. ${ }^{13}$

O eixo de sua estética teológica é a cristologia. Balthasar deseja mostra a beleza de Cristo ao mundo. Neste sentido a Gestalt de Cristo é o modo como o teólogo apresenta esta estética.

A figura de Cristo provoca uma percepção, na verdade, toda figura provoca isto. Toda percepção configura uma concepção ou cosmovisão. Para o teólogo toda percepção do pulchrum que é Cristo constitui uma objetividade em si. Não depende do sujeito constituir a beleza, senão que ela já está dada ${ }^{14}$. Uma vez posta a Gestalt, ela é "aparecente". Uma "figura aparecente" que se doa. De modo que se torna necessário certo complacência em relação à doação, ou seja, um querer chegar a esta "figura aparecente". Complacência está relacionada com aquilo que se dá, ou seja, a beleza que se doa que é Cristo. A estética desloca e provoca. Em Balthasar deve haver um desejo pela Gestalt de Cristo, provocando o desejo se encontra o Mistério.

Mistério experimentado pelo cristão em tantos elementos como na Palavra, na teologia, na celebração dos sacramentos, na liturgia. Pode-se assim afirmar a relação entre estética e Igreja, bem como estética teológica e sacramentos.

\begin{abstract}
Se, por fim, vale para a estética teológica que deve haver Igreja, ela conseguirá também salvaguardar através dos tempos o seu tesouro indiscutível de verdade, não obstante toda sua fragilidade (cf. 2Cor 4,7), como fascinante oferta, sobretudo pela celebração dos seus sacramentos de esperança que precisamente enquanto configurações estéticas participam da figura da revelação expõem a comunidade que celebra à crítica de sua autoglorificação, bem como à amável beleza de Deus sob as condições ambivalentes e discutíveis do tempo. ${ }^{15}$
\end{abstract}

Ao celebrar os sacramentos, ao realizar liturgicamente o seu ofício próprio que é a salvação da humanidade como instrumento do Cristo, a Igreja apresenta ao mundo esta estética teológica, a beleza de Cristo que salva. Con-

${ }^{13}$ BALTHASAR, H. U. La Gloire et la Croix, les aspects esthétiques de la révélation. Paris: Éditions Aubier-Montaigne, 1965, p. 9.

${ }^{14}$ Cf. FISICHELLA, R. Introdução à Teologia Fundamental. São Paulo: Loyola, 2011, p. 136. ${ }^{15}$ WOHLMUTH, J. "Beleza/Glória”. In: EICHER, P. (Ed.). Dicionário de Conceitos Fundamentais de Teologia. São Paulo: Paulus, 1993, pp. 51-55. 
tudo, composta por homens e sendo também uma instituição intramundana, a Igreja não está isenta de desvios históricos, assim a liturgia que expressa tal beleza pode distanciar, ao invés de conduzir à salvação. Neste sentido é que se percebeu a necessidade de uma renovação litúrgica, ou de uma reforma na liturgia.

\section{O Movimento litúrgico}

A renovação litúrgica na Igreja foi concretizada pelo Concílio Vaticano II. Para chegar a esta reforma realizada pelo Concílio é necessário fazer um breve percurso histórico. Mudanças ou reformas não ocorrem de forma brusca, assim aquilo que culminou no Concílio teve raízes anteriores, isto é, as mudanças foram se gestando durante certo período antecedente ao mesmo, com o anseio de uma reforma litúrgica. "Na liturgia, é o Movimento Litúrgico que vem questionar certos aspectos em vigor na forma de viver e celebrar dentro da Igreja, sendo assim, a maior influência para as reformas feitas durante o último Concílio Ecumênico da Igreja Católica Apostólica Romana". ${ }^{16}$ Tais anseios estão catalisados no chamado movimento litúrgico.

O movimento não é o único dentro de uma perspectiva de revigorar a vida cristã dentro da Igreja católica. Pode-se citar também o movimento bíblico, o movimento ecumênico, a nouvelle théologie, o movimento patrístico entre outros que surgem na mesma época histórica, "na segunda metade do século XIX, dentro da Igreja católica, nascem vários movimentos com a finalidade de revitalizá-la. Em parte, expressam o clima defensivo e restaurador, mas sob outros aspectos, abrem horizontes novos." ${ }^{17}$ Assim vai se gestando a possibilidade de uma reforma na liturgia.

Não é simples definir o que foi este movimento, já que se apresenta complexo e com certa evolução histórica. Afirmar-se, junto com João Batista Libanio, que

o início do movimento remonta, na segunda metade do século XIX, a Dom Guéranger (1805-1875), da abadia de Solesmes, na França, mas recebeu

\footnotetext{
${ }^{16}$ NEVES, P. D. A. "O Concílio Vaticano II e o design minimalista de Cláudio Pastro". Coletânea 22 (2012), pp. 197-214.

${ }^{17}$ BARGELLINI, E. "O Movimento litúrgico dos séculos XIX-XX, algumas perspectivas". In: CNBB (Org.). Raizes históricas e teológicas da Sacrosanctum Concilium. Brasília: CNBB, 2013, pp. 8-25.
} 
seu impulso mais recente a partir do Congresso de Malines, em 1909, por ocasião da apresentação por parte de D. Lambert Beauduin de um relatório sobre a participação dos fiéis no culto cristão. O mosteiro Mont César (Bélgica) se transformou no pólo de irradiação, com suas publicações que eram enviadas a todas as partes, difundindo as sementes renovadoras. ${ }^{18}$

Acrescente-se a esta definição de Libanio também o período da primeira metade do século XX. Portanto, um século antes do início do Concílio Vaticano II tal movimento passou por algumas fases. De início, dentro da perspectiva pela qual a Igreja passava, condenação do modernismo e restauração da vida cristã, o movimento encontra seu fundamento nos documentos papais, o Syllabus e a Quanta Cura de Pio IX, mas já com a Mirari Vos de Gregório XVI. Busca-se assim um retorno a uma época em que, pensava-se, a liturgia e a Igreja haviam chegado ao apogeu, a Idade Média, exatamente porque a modernidade propunha extinguir tudo que fosse medieval ${ }^{19}$. Com D. Guéranger o movimento busca redescobrir a beleza e eficácia da liturgia, mas dentro de seu contexto.

Em seguida o movimento entra em outra fase. Ele adquire tonalidade eminentemente pastoral. Após a participação do beneditino belga D. Beaudouin no Congresso Nacional de Obras Católicas de Malines o Movimento inicia esta fase. Agora as reflexões giram em torno de "uma participação ativa nos sagrados mistérios". ${ }^{20}$ A partir daí pensa-se a liturgia como elemento fundamental da doutrina cristã e como integrante da catequese. Há uma evolução no pensamento em torno da liturgia e da concepção da mesma na vida cristã. Em relação ao que constitui a essência do movimento, afirma-se que

o movimento teve como base quatro princípios, os quais buscavam primeiramente um retorno às fontes do cristianismo, a recuperação do sentido de mistério na liturgia, com foco na ideia de memorial da morte e ressurreição de Cristo como centro da celebração litúrgica, o entendimento da celebração eucarística como ação de graças e banquete, onde a

\footnotetext{
${ }^{18}$ LIBANIO, J. B. Concílio Vaticano II, em busca de uma primeira compreensão. São Paulo: Loyola, 2005, p.27.

${ }^{19}$ Cf. BARGELLINI, E. “O Movimento litúrgico dos séculos XIX-XX, algumas perspectivas". In: CNBB (Org.). Raizes históricas e teológicas da Sacrosanctum Concilium. Brasília: CNBB, 2013, pp. 8-25.

${ }^{20}$ Cf. NEVES, P. D. A. "O Concílio Vaticano II e o design minimalista de Cláudio Pastro". Coletânea 22 (2012), pp. 197-214.
} 
comunidade reúne-se para fração do pão e a participação ativa dos fiéis na liturgia, uma vez que o movimento insistia no caráter celebrativo e, portanto, eclesial do culto. ${ }^{21}$

Com o aprofundamento teológico acerca da liturgia se pode melhor acentuar a essência do mistério pascal celebrado. Tal aprofundamento permitiu vislumbrar um retorno às origens do cristianismo.

$\mathrm{O}$ contexto de uma volta às fontes possibilitou retirar excessos acumulados ao longo da história e que não constituem o núcleo central e essencial, isto é, aquilo que faz parte da grande Tradição da Igreja. Sobre isto fala João Batista Libanio

vários estudiosos se dedicaram às pesquisas científicas e históricas a fim de passar pelo crivo da Tradição (com T maiúscula) uma série de pequenas tradições litúrgicas acumuladas, que, no decorrer do tempo, se desgastaram e perderam elementos importantes da compreensão da liturgia, seja dos tempos patrísticos, seja da própria Alta Idade Média, em favor de correntes teológicas que reagiam a questões polêmicas. ${ }^{22}$

Havia não apenas o anseio, mas um grande trabalho em busca de renovação. As produções acadêmicas e as pesquisas científicas em larga escala foram o arcabouço teórico da grande reforma executada pelo Concílio.

Tais produções e a convicção de seus produtores são lentamente recebidas pelo magistério pontifício, legitimando assim a causa litúrgica. Sobre isto afirma Libanio que

nesse ambiente teológico de maior abertura em relação ao mistério que se celebra, o movimento litúrgico ensaiava inovações concretas que lentamente passaram a levar à modificação de ritos e celebrações. Já desde Pio X se vinham fazendo essas mudanças. Pio XII promoveu sobretudo uma reforma da Semana Santa e amenizou a disciplina do jejum eucarístico. Parecem coisas pequenas, mas se ia criando esse clima de criatividade, de novidade, e de busca de resposta à nova situação. $^{23}$

\footnotetext{
${ }^{21}$ NEVES, P. D. A. "O Concílio Vaticano II e o design minimalista de Cláudio Pastro". Coletânea 22 (2012), pp. 197-214.

${ }^{22}$ LIBANIO, J. B. Concílio Vaticano II. São Paulo: Loyola, 2005, p. 27.

${ }^{23}$ LIBANIO, J. B. Concílio Vaticano II. São Paulo: Loyola, 2005, p. 27.
} 
A reflexão teológica avança e com isso a possibilidade de mudanças se torna mais significativa e eminente. Entretanto, tais mudanças não foram recebidas pacificamente. Como, por exemplo, aqui no Brasil "na outra vertente leiga, estava a Congregação Mariana, que se manteve distanciada, arredia e desconfiada diante das inovações litúrgicas, especialmente promovida pela Juventude Estudantil Católica (JEC) e pela Juventude Universitária Católica (JUC)"24. São posturas antagônicas que irão permanecer assim até mesmo dentro do próprio Concílio.

O que chega até o Concílio é o resultado de um processo histórico. Um milênio de uma liturgia que foi se tornando cada vez mais clerical, sem nenhuma forma de participação dos fieis, que se tornam apenas assistentes passivos da missa ${ }^{25}$. Estes ficam distante da liturgia celebrada. Se de um lado há os promotores de um pensamento da necessidade de uma reforma, por outro há inflexíveis defensores da liturgia vigente, isto é, pós-tridentina. Ariovaldo da Silva afirma que "o movimento teve opositores ferrenhos que o colocavam sob suspeita, provocando acaloradas discussões" ${ }^{26}$, e enumera uma série de expressões usadas pelos $\operatorname{mesmos}^{27}$.

Um documento que marcou decisivamente esta perspectiva de aprimoramento litúrgico foi a encíclica Mediator Dei do papa Pio XII. De certa forma o papa absorve o espírito de renovação que estava sendo gestado. Trabalhos e pesquisas acadêmicas foram assimilados pelo magistério pontifício. Ariovaldo ressalta que

uma voz forte neste debate foi a de Pio XII que publicou, em 1947, a encíclica Mediator Dei sobre a liturgia, documento decisivo para a causa litúrgica, especificando alguns conceitos e reconhecendo os esforços desenvolvidos pelo movimento litúrgico. O próprio papa introduziu várias reformas parciais na liturgia. Em 1948, nomeou uma comissão para a reforma da liturgia; em 1951 reformou a Vigília Pascal; em 1955, reformou a Semana Santa e simplificou rubricas e textos da Liturgia das Horas; em

${ }^{24}$ LIBANIO, J. B. Concílio Vaticano II. São Paulo: Loyola, 2005, p. 27-28.

${ }^{25}$ Cf. SILVA, J. A. "Avanços e retrocessos no movimento litúrgico no Brasil”. Revista de Cultura Teológica 31 (2000), pp 109-131.

${ }^{26}$ SILVA, J. A. "Avanços e retrocessos no movimento litúrgico no Brasil”. Revista de Cultura Teológica 31 (2000), pp. 109-131.

${ }^{27}$ Cf. SILVA, J. A. "Avanços e retrocessos no movimento litúrgico no Brasil”. Revista de Cultura Teológica 31 (2000), pp 109-131. 
1956, introduziu a missa vespertina; e em 1955 e 1958, publicou duas instruções sobre a música sacra. ${ }^{28}$

Estavam lançadas não somente as bases, mas preparada toda a estrutura para uma reforma litúrgica.

\title{
4. A Renovação da liturgia
}

Efetuada pelo Concílio Vaticano II a reforma é fruto de uma longa reflexão e produção sobre a liturgia. Foi sendo acentuado paulatinamente o caráter eclesiológico e cristológico da mesma. A liturgia assume fortemente a conotação da presença de Cristo, não apenas nas espécies consagradas, mas na Palavra e no povo de Deus reunido. Sobre isto afirma Pere Tena:

\begin{abstract}
El Concilio Vaticano II, en la Constitución Sacrosanctum Concilium, asumió la doctrina de Mediator Dei, y la situó de una forma más explícita en el contexto de una teologia de la história de la salvación (n. 5); destacó asimismo el signo de la palabra como una de las presencias de Cristo (n. 7), e insistió fuertemente en la condición sacerdotal del pueblo cristiano, llamado y urgido a una participación activa y consciente (n. 14), sacando las consecuencias prácticas de reforma y introducción de la lengua vulgar (nn. 21 y 36$).{ }^{29}$
\end{abstract}

No Concílio a liturgia deixa de ter um aspecto passivo no corpus eclesial para adquirir a centralidade que lhe é própria e que não é estranha à comunidade primitiva. A liturgia é o ponto fulcral de toda a vida da Igreja.

A reforma atua principalmente em retomar o caráter teológico da liturgia. Mas também há uma reforma prática, dos ritos. É o que afirma Libanio. Segundo ele

o movimento litúrgico anterior ao Concílio trabalhou em dois planos. Um, mais de fundo, atingia a compreensão mesma da liturgia. Outro, mais prático, tocava as mudanças dos ritos. No primeiro plano, procurou-se penetrar no mistério da Igreja que celebra. Logo se valorizou o caráter de

\footnotetext{
${ }^{28}$ SILVA, J. A. "Avanços e retrocessos no movimento litúrgico no Brasil”. Revista de Cultura Teológica 31 (2000), pp. 109-131.

${ }^{29}$ TENA, P. "La reforma litúrgica promovida por el Concilio Vaticano II". Anuário de História de la Iglesia 10 (2001), pp. 189-198.
} 
assembleia e de comunidade das celebrações, rompendo a atitude passiva, individualista, com que as pessoas assistiam aos atos litúrgicos. Essa atitude básica provocou as primeiras reformas nos ritos. ${ }^{30}$

Associada a uma mudança de pensamento ocorre uma mudança de rito, como também já preconizava o movimento litúrgico. Para Libanio o fundamental foi esta mudança de pensar, mas de forma mais sensível se percebeu mais uma mudança de ritos. Esta deu-se como consequência daquela, ou seja, "as transformações dos ritos, a parte mais perceptível da reforma litúrgica, decorreram simplesmente dessa nova compreensão litúrgico-eclesiológica" ${ }^{31}$. A ênfase está na comunidade reunida, que celebra de forma livre e consciente o mistério pascal. Isto aparece de modo claro no documento conciliar sobre a liturgia.

O texto da constituição Sacrosanctum Concílium foi aprovado na segunda sessão, no de 1963, e traz no início a contextualização da liturgia dentro do mistério da Igreja ${ }^{32}$. O documento além de apontar os princípios da reforma no capítulo primeiro, nos capítulos seguintes legisla sobre a Eucaristia, os sacramentos e sacramentais, o ofício divino, o ano litúrgico, a música sacra, a arte sacra e as sagradas alfaias, abordando de forma universal a liturgia. Para Alberto Beckhäuser a aprovação da Sacrosanctum Concilium como primeiro documento do Concílio Vaticano II permitiu um melhor acercamento dos temas posteriores, igualmente importantes para a atualização empreendida pelo Concílio. Para Beckhäuser

a tomada de posição sobre a compreensão da liturgia, fugindo do ritualismo e do legalismo reinantes, abriu caminho para uma compreensão da Igreja segundo o mistério, da dignidade e missão dos leigos, da compreensão dos diversos ministérios na Igreja a serviço do povo de Deus profético sacerdotal e real. A própria Palavra de Deus foi vista sob nova perspectiva à luz da Economia da Salvação. ${ }^{33}$

Todo o Concílio recebe forte influência deste documento. Com uma compreensão da liturgia como centro do mistério da Igreja o Vaticano II pode aprofundar melhor uma renovação de toda a vida eclesial.

\footnotetext{
${ }^{30}$ LIBANIO, J. B. Concílio Vaticano II. São Paulo: Loyola, 2005, p. 161.

${ }^{31}$ LIBANIO, J. B. Concílio Vaticano II. São Paulo: Loyola, 2005, p. 163.

${ }^{32} \mathrm{Cf}$. Sacrosanctum Concilium n. 2

33 BECKHÄUSER, A. "Introdução”. In: Sacrosanctum Concilium, texto e comentários. São Paulo: Paulinas, 2012, pp. 7-12.
} 


\section{Conclusão}

O esforço de teólogos em produzir uma teologia especulativa possibilita abrir novas perspectivas. Construir uma estética teológica que tenha como fulcro o próprio Cristo, demonstra a originalidade de Hans Urs von Balthasar. Há uma busca de compreensão mais objetiva do mistério. Com isso ocorre o aprofundamento desta compreensão, e Balthasar apresenta uma interpretação da mensagem cristã a partir da categoria do belo. A expressão máxima do transcendente. É a construção de uma teologia que transparece como preocupação deste teólogo, muito mais do que uma estética. Esta é o método para chegar àquela. A via estética, em Balthasar, revela o esvaziamento de Jesus e o horror da cruz como um único e mesmo ato de salvação da humanidade. Não pode haver um conhecimento de Deus sem aquela via, bem como não pode haver salvação sem a manifestação do belo. O que abre perspectiva para uma reflexão sobre a liturgia como manifestação do belo e como movimento de salvação. Ação de Cristo que atualiza o mistério pascal na história da humanidade.

O processo histórico que possibilitou ao Concílio Vaticano II a efetivação de uma reforma litúrgica recuperou este pensamento, a liturgia não é uma ação periférica da Igreja. No mistério celebrado está o fundamento de toda a vida eclesial, a razão de ser da Igreja. Ao recuperar este modo de pensar o movimento litúrgico se coloca como promotor da reforma na liturgia. A reforma empreendida pelo Concílio não teve precedentes na história da Igreja. A amplitude, a rapidez de sua realização e a intensidade das decisões tomadas mostra o que significou o Vaticano II e a reforma para a vida eclesial. Um trabalho eclesial fascinante e com perspectiva para o futuro da vida cristã. Longe de estar totalmente concretizado, o Concílio necessita ainda ser compreendido e atualizado para o contexto atual, tão marcado pelas rápidas transformações sociais, econômicas e tecnológicas. Deve ser sempre um paradigma fundamental o axioma da ecclesia semper reformanda est. 


\section{Referências bibliográficas}

BALTHASAR, H. U. La Gloire et la Croix, les aspects esthétiques de la révélation. Paris: Éditions Aubier-Montaigne, 1965.

BARGELLINI, E. "O Movimento litúrgico dos séculos XIX-XX, algumas perspectivas". In: CNBB (Org.). Raizes históricas e teológicas da Sacrosanctum Concilium. Brasília: CNBB, 2013, pp. 8-25.

BECKHÄUSER, A. "Introdução". In: Sacrosanctum Concilium, texto e comentários. São Paulo: Paulinas, 2012, pp. 7-12.

FEAGIN, S. L. "Beleza". In: AUDI, R. (Ed.). Dicionário de Filosofia de Cambridge. São Paulo: Paulus, 2006, pp. 74-75.

FISICHELLA, R. "Beleza". In: LATOURELLE, R.; FISICHELLA, R. (Ed.). Dicionário De Teologia Fundamental. Petrópolis: Vozes, 1994, pp. 107-108.

FISICHELLA, R. "Hans Urs von Balthasar". In: LACOSTE, J-Y. (Ed.). Dicionário Crítico de Teologia. São Paulo: Paulinas, 2004, pp. 231-238.

FISICHELLA, R. Introdução à Teologia Fundamental. São Paulo: Loyola, 2011.

LIBANIO, J. B. Concílio Vaticano II, em busca de uma primeira compreensão. São Paulo: Loyola, 2005.

NEVES, P. D. A. "O Concílio Vaticano II e o design minimalista de Cláudio Pastro”. Coletânea 22 (2012), pp. 197-214.

PONTIFÍCIO CONSELHO PARA A CULTURA. "La Via pulchritudinis: Cammino privilegato di evangelizzacione e di dialogo". Disponível em: <http://www.vatican.va/roman_curia/pontifical_councils/ cultr/documents/rc_pc_cultr_doc_20060327_plenary-assembly_finaldocument_it.html>. Acesso em 17 de outubro de 2014.

SILVA, J. A. "Avanços e retrocessos no movimento litúrgico no Brasil". Revista de Cultura Teológica 31 (2000), pp. 109-131.

TENA, P. "La reforma litúrgica promovida por el Concilio Vaticano II”. Anuário de História de la Iglesia 10 (2001), pp. 189-198.

WOHLMUTH, J. “Beleza/Glória”. In: EICHER, P. (Ed.). Dicionário de Conceitos Fundamentais de Teologia. São Paulo: Paulus, 1993, pp. 51-55. 
Tiago Geyrdenn de Oliveira Gomes Bacharel em Teologia pela Faculdade Católica de Fortaleza Aluno do Programa de Estudos de Pós-Graduação em Teologia pela PUC-SP

(mestrado)

São Paulo / SP - Brasil

E-mail: geyrdenn@yahoo.com.br

Recebido em: 21/05/15

Aprovado em: 16/03/16 